\title{
Frailty indexed classification of Bangladeshi older adults' physio-psychosocial health and associated risk factors- a cross- sectional survey study
}

Mohammad Meshbahur Rahman ${ }^{1,2^{*}}$, Mohammad Hamiduzzaman ${ }^{3}$, Mst. Saleha Akter $^{4}$, Zaki Farhana ${ }^{5}$, Mohammad Kamal Hossain ${ }^{6}$, Mohammad Nayeem Hasan ${ }^{6}$ and Md. Nazrul Islam

\begin{abstract}
Background: Frailty is associated with healthy ageing, and it has been identified as a means of measuring older adults' physio-psychosocial health. We know about the ageing trends and common diseases of older adults living in South Asia, but literature to date does not widely feature their health status based on frailty, especially in Bangladesh. This study aims to understand the prevalence of frailty in Bangladeshi older adults; classify their health status; and investigate associated risk factors.

Methods: A cross-sectional study was conducted in the north-eastern region (i.e. Sylhet City Corporation) of Bangladesh. Four hundred participants aged 55 years and above were randomly selected, attended a health assessment session and completed a multi-indicator survey questionnaire. We developed a 30-indicator Frailty Index $\left(\mathrm{Fl}_{30}\right)$ to assess the participant's health status and categorized: good health (no-frailty/Fit); slightly poor health (mild frailty); poor health (moderate frailty); and very poor health (severe frailty). Pearson chi-square test and binary logistic regression analysis were conducted.

Results: The participants' mean age was 63.6 years, and $61.6 \%$ of them were assessed in poor to very poor health (moderate frailty/36.3\% - severe frailty/25.3\%). The eldest, female and participants from lower family income were found more frailty than their counterparts. Participants aged 70 years and above were more likely (adjusted OR: 4.23, 95\% Cl: $2.26-7.92, p<0.0001$ ) to experience frailty (medical conditions) than the pre-elderly age group (55-59 years). Female participants were more vulnerable (adjusted $\mathrm{OR}=1.487,95 \% \mathrm{Cl}: 0.84-2.64, p<0.0174$ ) to frailty (medical conditions) than male. Also, older adults who had higher family income (Income>\$473.3) found a lower risk (adjusted OR: $0.294,95 \% \mathrm{Cl}: 0.11-0.76, p<0.011$ ) of frailty (poor health).
\end{abstract}

Conclusion: Our study results confirm the prevalence of frailty-related disorders in Bangladeshi older adults and highlight the importance of targeted clinical and community-led preventive care programs.

Keywords: Older adults, Physical and mental health, Frailty index, Bangladesh

\footnotetext{
* Correspondence: meshbahur.rahman@brfbd.org

1 Biomedical Research Foundation, Dhaka 1230, Bangladesh

2Basic Science Division, World University of Bangladesh, Dhaka 1230, Bangladesh

Full list of author information is available at the end of the article
}

(C) The Author(s). 2021 Open Access This article is licensed under a Creative Commons Attribution 4.0 International License, which permits use, sharing, adaptation, distribution and reproduction in any medium or format, as long as you give appropriate credit to the original author(s) and the source, provide a link to the Creative Commons licence, and indicate if changes were made. The images or other third party material in this article are included in the article's Creative Commons. licence, unless indicated otherwise in a credit line to the material. If material is not included in the article's Creative Commons licence and your intended use is not permitted by statutory regulation or exceeds the permitted use, you will need to obtain permission directly from the copyright holder. To view a copy of this licence, visit http://creativecommons.org/licenses/by/4.0/ The Creative Commons Public Domain Dedication waiver (http://creativecommons.org/publicdomain/zero/1.0/) applies to the data made available in this article, unless otherwise stated in a credit line to the data. 


\section{Background}

Increasing longevity comes with a high rate of morbidity, comorbidity and chronic conditions in South Asian older adults. The population of older adults is increasing in South Asia, and this steady increase is also evident in the change of life expectancy from 62.8 years in 2000 to 69.5 years in 2018 [1,2]. Healthy ageing refers to an absence of physical and psychological conditions, but all South Asian countries ranked low in geriatric care, as such many older adults live with weakness, pain, obesity, eyesight, hearing loss, high blood pressure, diabetes, heart disease, and psychological problems [1]. These conditions are progressive in nature - require acute care needs - but are not being reported until they become severe. In India, Kashikar and Nagarkar (2016) reported the prevalence of frailty as 26\% (Pre-frail- 63.6\%; and Non-frail-10.4\%) [3], while Ali et al. (2019) found frailty in 55.4\% Pakistani older adults (Intermediate frail 44.6\%) [4]. In Nepal, the prevalence of frailty was $46.2 \%$ (men - 46.3\%; women - 46.1\%), and this prevalence was $15.2 \%$ in Sri Lanka (Pre-frail - 48.5\%) [5]. The identified risk factors were level of education, occupation, older age, smoking, isolation, breathing problems, pain, fatigue, and falls and fractures [6]. Growing older population and their health conditions challenge public health leaders and clinicians in South Asia, especially in Bangladesh where geriatric care services and resources are limited.

In Bangladesh, the number of older adults has increased from 5.2 million in 1990 to 15 million in 2017, and about half of them experience the complications of malnourishment and diverse types of disability $[1,7,8]$. The literature indicates the older adults' sedentary lifestyle that deteriorates their physical strength and intellectual capacity leading to an incompetence in daily living and a prevalence of injuries, falls and poor quality of life [2]. In addition, the prevalence of isolation, anxiety and depression are common in these older adults [7]. Their physical and mental health and health service utilization fluctuate based on socio-demographic structures and living circumstances [e.g. age, gender, education, occupation, income, lifestyle and family]. Fear of dependency on family members in the older adults because of illness is higher than their economic reliance $[8,9]$. There is an increasing research interest on aging trends and diseases, but the elderly health status remains under-assessed in relation to their frailty, in turn bestpractice was absent in making clinical and public health decisions for them.

Frailty is a state of vulnerability characterized by physio-psychosocial changes and loss of resistance to stressors caused by accumulated age-related deficits [10, 11]. Investigations on the older adults' health relate the frailty with a risk of various negative health and well- being outcomes including physical weakness, falls, injuries, disability, poor quality of life, dementia, hospitalization, emergency department presentation and nursing home placement $[12,13]$. As such, a Frailty Index approach is an effective means of elderly health measure [12, 13]. In Bangladesh, majority of the community-dwelling older adults have a tendency of self-care and avoiding hospitals, have health illiteracy, poverty lack of health services, and their frailty-related disorders remain undiagnosed and untreated. This unhealthy ageing causes a care and financial burden for the older adults and their family members, service providers and the community.

Studies are limited on older adult's frailty in South Asia, and the available studies suggest contextual investigation of their frailty and health conditions [4, 14-20]. Few studies on ageing conducted in Bangladesh reported the importance of preventive and primary healthcare programs for older adults [7, 9, 21-28]. But having a lack of research on the older adults' frailty and its associates caused an absence of evidence-based geriatric practice and service provision. Also, the studies conducted in Bangladesh did not investigate the country's northeastern population group, where most of the older adults presented comorbidity and multimorbidity [6]. We, therefore, investigate the prevalence of frailty, using a Frailty Index, in community-dwelling older adults in the north-eastern region of Bangladesh and classify their health status, and explore associated socio-demographic covariates.

\section{Methods}

\section{Ethics and permission for data collection}

Ethics approval for this study (Project Number: PS/2018/ 1/11) was granted by the University Research Center, Shahjalal University of Science \& Technology, Bangladesh and formal permission for data collection was sought from Sylhet Civil Surgeon Office, Bangladesh.

\section{Study design}

A cross-sectional study design, involving a person-centered general health assessment and a self-administered survey, was employed in this research.

\section{Setting and participants}

This study was conducted from January 2018 to December 2019 in the north-eastern region (i.e. Sylhet City Corporation) of Bangladesh. In Bangladesh, while elderly cut-off age is 60 years and the national average of life expectancy is 72.05 years, literature notes that people who live in Sylhet have a lower life expectancy than the national average [29]. It is evident in literature that physical fitness or health condition of a person starts decline at the age of 55 years and present signs of aging (wrinkles, dullness of skin, weakness, dry skin, blotchiness and age spots) [30-34]. In Sylhet, the 
health literacy is low and the people are not aware of their healthcare needs until their problems are manifested [35]. As a result, we approached the people aged 55 years and above through Sylhet City Corporation. The inclusion criteria were: (i) aged 55 years and older; (ii) living in Sylhet City Corporation; and (iii) agreed to participate in a general health assessment and an interview. We used the singlestage cluster sampling, and this resulted in a random sample size of 400 participants from 13 administrative wards of the City Corporation. The administrative wards were selected through random number generated by RProgramming language.

\section{Data collection}

A multi-indicator survey design was employed to explore diverse health issues and conditions of the participants. In accordance with the standards of Helsinki Declaration of 2000 (revised version), written informed consent was obtained from each of the participants. After formal consent, the health profile of each participant was collected, through a general health assessment and a structured questionnaire, including self-reported health problems, biomarkers, performance of daily activities and sociodemographic information. Necessary medical equipment was provided to a trained public health assistant to assess and collect anthropometric data.

\section{Outcome measures \\ General health assessment of height, weight, BMI, BP and RBS}

The following Table 1 presents the measurement system of basic health indicators.

\section{Frailty index $\left(\mathrm{FI}_{30}\right)$ measurement and coding of variables}

Developing a list of variables is important to compute frailty, while there is no uniform list and researchers used different variables in calculating the Frailty Index. We consulted with clinicians and an epidemiologist, included 30 categorical variables specific to the older adults' frailty and relevant to our socioeconomic contexts, following the works of Gobbens et al., 2010; Searle et al., 2008; and Rockwood et al., 2018 (Table 2) $[36,37]$. Categorical variables were coded using the convention that ' 0 ' indicated the absence of the deficit, and ' 1 ' the presence of a deficit [36-38]. For some categorical variables (e.g. self-rated health, BMI etc.) that comprised one or more intermediate responses (e.g. 'average' or 'frequently'), we considered the additional value of '0.25', ' $0.5^{\prime}$ and '0.75'. We used the short form of Geriatric Depression Scale and a list of 15 questions in a separate questionnaire to collect data [39]. The mathematical formula used for calculating $\mathrm{FI}_{30}$ in this study was as follows:

$$
F I=\frac{\sum \text { Deficits }}{30-\sum \text { Missing Values }}
$$

There was no missing value in the datasets and the calculated $\mathrm{FI}_{30}$ was a continuous score. Obviously, $\mathrm{FI}_{30}$ lies between 0 and 1, however, it was categorized, according to Clegg et al. (2016): $\mathrm{FI}_{30} \leq 0.12$ (No Frailty or Fit/Good Health); $0.12<\mathrm{FI}_{30} \leq 0.24$ (Mild Frailty/Slightly Poor Health); $0.24<\mathrm{FI}_{30} \leq 0.36$ (Moderate Frailty/Poor Health); and $\mathrm{FI}_{30}>0.36$ (Severe Frailty/Very Poor Health) for analysis purposes [40]. We further classified the $\mathrm{FI}_{30}$ into: No Frailty/Fit (Fairly Healthy, $\mathrm{FI} \leq 0.24$ ); and Frailty (Medical Conditions, FI $>0.24$ ) to perform the multivariable binary logistic regression.

\section{Data analysis}

We employed frequency distribution to understand the participants' demographics. The relationships between the participants' frailty (physio-psychosocial health) and socio-demographic factors were tested using bivariate analysis. The Pearson chi-square test was performed to observe the significant association between $\mathrm{FI}_{30}$ and socio-demographic variables. Student t-test of Frailty Index was employed to assess the mean difference between male and female older adults. The degree of

Table 1 Measurements of Height, Weight, BMI, BP and RBS

\begin{tabular}{|c|c|c|}
\hline Health Indicators & Instruments & Measurement procedures \\
\hline Height (m) & Height measuring scale (Stadiometer) & $\begin{array}{l}\text { - Stand without shoes and simple summer clothes } \\
\text { - Look straight ahead and keep shoulders to level }\end{array}$ \\
\hline Weight (Kg) & Weight measuring scale (Seca Digital) & $\begin{array}{l}\text {-Keeping normal Summer clothes } \\
\text { - Keeping the respondents simple as far as possible } \\
\text { during the measurement }\end{array}$ \\
\hline $\mathrm{BMI}\left(\mathrm{Kg} / \mathrm{m}^{2}\right)$ & Computer & $B M I=\frac{\text { Weight }(K g)}{\text { Height }(m)^{2}}$ \\
\hline $\mathrm{BP}(\mathrm{mmHg})$ & $\begin{array}{l}\text { Electronic BP Monitor (OMB) } \\
\text { Model: BP-1307 }\end{array}$ & $\begin{array}{l}\text { - Well seated } \\
\text { - After } 5 \text { min rest } \\
\text { - Average of three consecutive readings }\end{array}$ \\
\hline $\mathrm{RBS}(\mathrm{mmol} / \mathrm{L})$ & Digital RBS Machine (VivacheckM Ino.), Model: VGM01 & $\begin{array}{l}\text { - Time between breakfast and lunch } \\
\text { - Time between lunch and dinner }\end{array}$ \\
\hline
\end{tabular}




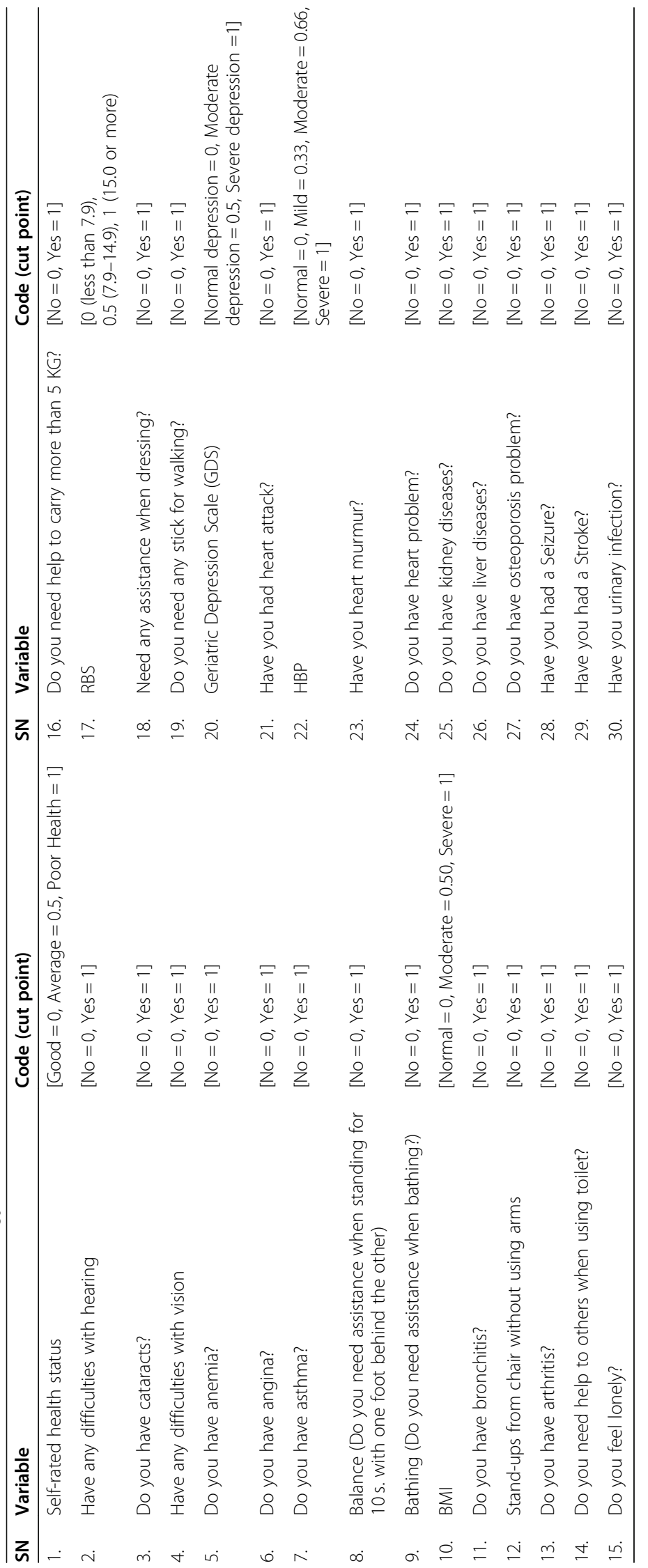


associated risk factors was assessed by univariable [unadjusted odd ratio (unadjusted OR)] and multivariable odds ratios [adjusted odds ratio (adjusted OR)] obtained from the binary logistic regression model [41], where $\mathrm{FI}_{30}$ was a binary dependent variable, and physiopsychosocial variables were independent variables. This project's data management and statistical analyses were carried out through IBM SPSS Statistics 20.0.

To ensure reliability and validity of the study results, we used a number of techniques: (i) employ SPSS 20.0 in data analysis; (ii) explore descriptive statistics of the sample (socio-demographic items) and their means and standard deviations; (iii) reliability analyses of the data used in calculating $\mathrm{FI}_{30}$ (Cronbach's alpha, the reliability coefficient values for the variables used in $\mathrm{FI}_{30}$ is found 0.70); and (iv) use of two statistical techniques, namely chi-square test and logistic regression [42].

\section{Results}

\section{Baseline demographics and prevalence of frailty}

The baseline demographics are presented in Fig. 1 and Table 3. Mean age of the participants was $63.61( \pm 8.73)$ years, with an age range of $55-100$ years. More than half of them $(57.3 \%)$ were male and illiteracy rate was $56.8 \%$. One-third were engaged in different services and the rest of them were retired, housewife and small business with limited functional activities. Isolation because of divorce/ widowed was identified as a strong predictor of elderly health (i.e. about $20 \%$ participants were divorced/ widowed). Smoking habit was found in $27 \%$ participants.

The frailty index $\left(\mathrm{FI}_{30}\right)$ ranged 0.05 to 0.71 where the mean $\mathrm{FI}_{30}$ was 0.28 . Analysis of the health status reflecting on Frailty Index, most of the participants were observed in moderate frail or poor health $(n=145$ $(36.3 \%)$ ) and $25.3 \%$ were severe frailty. Results also reported that maximum older adults $(61.6 \%)$ were experiencing 'poor to very poor' health condition (moderate frailty to severe frailty), whereas only $8.5 \%$ were found fit or in good health (Fig. 1.a). Overall, the mean test (independent t-test) of the frailty index found a significant difference between male and female (mean FI of male: 0.271 (standard deviation: 0.118); mean FI of female: 0.303 (standard deviation: 0.114); $p=0.006$ ). It was important to note that female older adults presented more health complexities with the increase of frailty severity and female older adults were severely frailty (50.5\% vs 49.5\%) compared with their male counterparts (Fig. 1.b).

\section{Association between $\mathrm{FI}_{30}$ and socio-demographic components}

The association between older adults' age groups and frailty was found statistically significant $(p<0.0001)$. Additionally, the participants' gender, education, occupation, marital status and income were significantly $(p<$ 0.05) associated with frailty (Table 3 ).

\section{Risk factors of the older adults' frailty-related disorders}

The physio-psychosocial risk factors of frailty were identified by unadjusted odds ratio and adjusted odds ratio with $95 \%$ confidence intervals after adjusting for a number of important covariates (Table 4). The participants who were of older age, female, were not involved with an occupation or activity outside the home and had low income were more likely to experience frailty severity than their counterparts. The older adults aged 60-64 years were significantly more frail (unadjusted odds ratio:

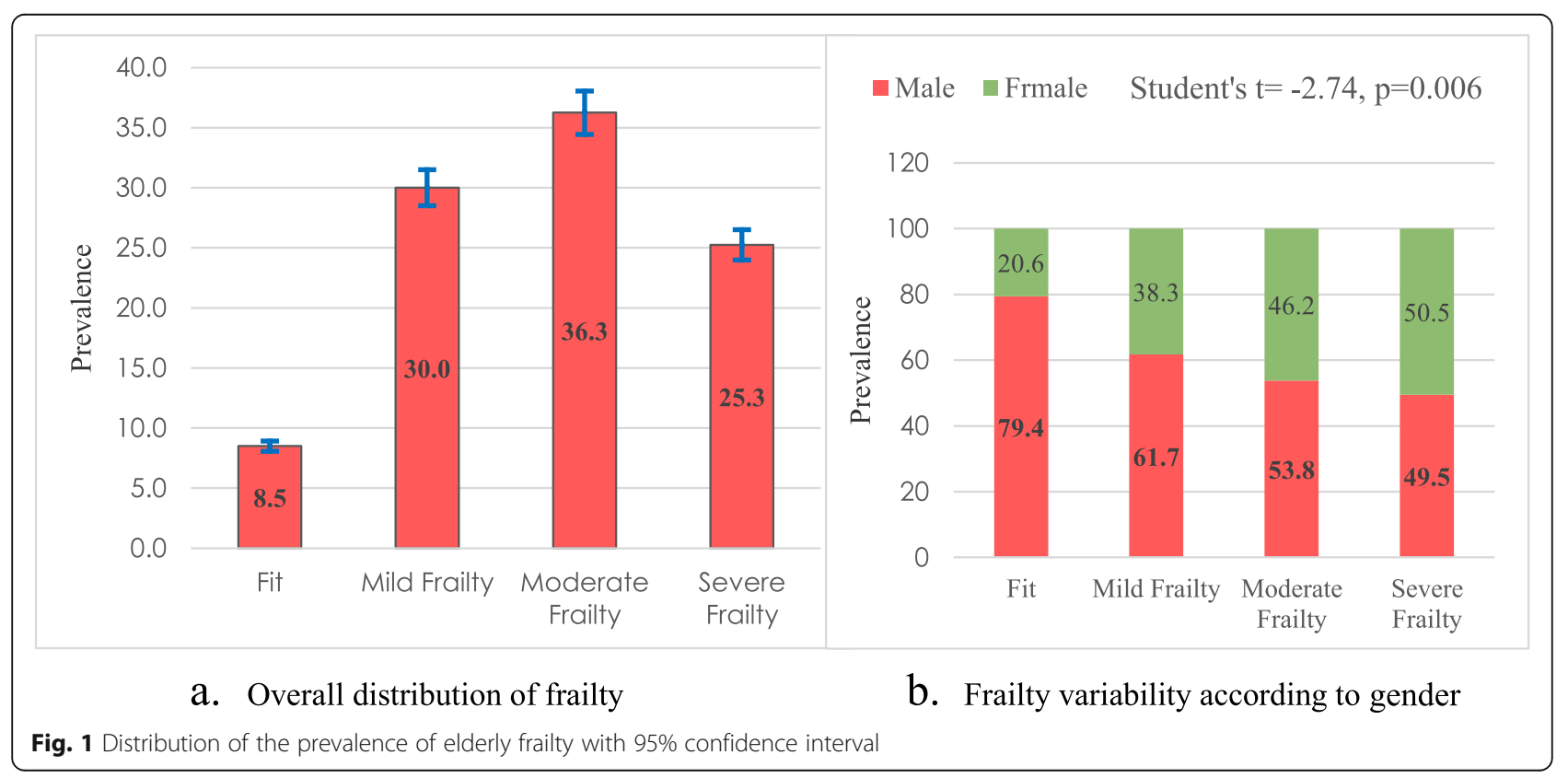


Table 3 Association of $\mathrm{Fl}_{30}$ with socio-demographic components

\begin{tabular}{|c|c|c|c|c|c|c|}
\hline \multirow[t]{2}{*}{ Characteristics } & Frequency & $\begin{array}{l}\text { Good Health/Fit } \\
{[\mathrm{FI} \leq 0.12]}\end{array}$ & $\begin{array}{l}\text { Slightly Poor Health/Mile } \\
\text { Frailty }[0.12<\mathrm{FI} \leq 0.24]\end{array}$ & $\begin{array}{l}\text { Poor Health/Moderate } \\
\text { Frailty }[0.24<\mathrm{FI} \leq 0.36]\end{array}$ & $\begin{array}{l}\text { Very Poor Health/ } \\
\text { Severe Frailty } \\
{[\mathrm{FI}>0.36]}\end{array}$ & \multirow[t]{2}{*}{$P$-value } \\
\hline & n (\%) & n (\%) & n (\%) & n (\%) & n (\%) & \\
\hline \multicolumn{7}{|l|}{ Age of the respondent } \\
\hline $55-59$ & 145(36.3) & $22(15.2)$ & $51(35.2)$ & $53(36.6)$ & $19(13.1)$ & \multirow[t]{4}{*}{0.0001} \\
\hline $60-64$ & $90(22.5)$ & $4(4.4)$ & $21(23.3)$ & $40(44.4)$ & $25(27.8)$ & \\
\hline $65-69$ & $66(16.5)$ & $4(6.1)$ & $30(45.5)$ & $19(28.8)$ & $13(19.7)$ & \\
\hline $70+$ & $99(24.8)$ & $4(4.0)$ & $18(18.2)$ & $33(33.3)$ & $44(44.4)$ & \\
\hline \multicolumn{7}{|l|}{ Gender } \\
\hline Male & $229(57.3)$ & $27(11.8)$ & $74(32.3)$ & $78(34.1)$ & $50(21.8)$ & \multirow[t]{2}{*}{0.012} \\
\hline Female & $171(42.8)$ & $7(4.1)$ & $46(26.9)$ & $67(39.2)$ & $51(29.8)$ & \\
\hline \multicolumn{7}{|l|}{ Education } \\
\hline Illiterate & $227(56.8)$ & $15(6.6)$ & $62(27.3)$ & $80(35.2)$ & 70 (30.8) & \multirow[t]{2}{*}{0.018} \\
\hline Literate & $173(43.2)$ & $19(11.0)$ & $58(33.5)$ & $65(37.6)$ & $31(17.9)$ & \\
\hline \multicolumn{7}{|l|}{ Occupation } \\
\hline Service & $116(29.0)$ & $17(14.7)$ & $41(35.3)$ & 45 (38.8) & $13(11.2)$ & \multirow[t]{2}{*}{0.0001} \\
\hline Housewife/Others & $284(71.0)$ & $17(6.0)$ & $79(27.8)$ & $100(35.2)$ & $88(31.0)$ & \\
\hline \multicolumn{7}{|l|}{ Marital Status } \\
\hline Married & $320(80.0)$ & $30(9.4)$ & $102(31.9)$ & $121(37.8)$ & $67(20.9)$ & \multirow[t]{2}{*}{0.001} \\
\hline Widow/Divorce & $80(20.0)$ & $4(5.0)$ & $18(22.5)$ & $24(30.0)$ & $34(42.5)$ & \\
\hline \multicolumn{7}{|l|}{ Smoking Behavior } \\
\hline Non-Smoker & $294(73.5)$ & $21(7.1)$ & $83(28.2)$ & $115(39.1)$ & $75(25.5)$ & \multirow[t]{2}{*}{0.107} \\
\hline Smoker & $106(26.5)$ & $13(12.3)$ & $37(34.9)$ & $30(28.3)$ & $26(24.5)$ & \\
\hline \multicolumn{7}{|c|}{ Monthly Family Income in Taka (Dollars, considering \$1 = 84.52 BDT, Accessed: October 06, 2020) } \\
\hline Less than $10,000(\$ 118.3)$ & $118(29.5)$ & $3(2.5)$ & $32(27.1)$ & $44(37.3)$ & $39(33.1)$ & \multirow[t]{5}{*}{0.020} \\
\hline $10,000-20,000(\$ 118-\$ 236.6)$ & $139(34.8)$ & $16(11.5)$ & $41(29.5)$ & $51(36.7)$ & $31(22.3)$ & \\
\hline $\begin{array}{l}20,000-30,000 \\
(\$ 236.6-\$ 354.9)\end{array}$ & $85(21.2)$ & $11(12.9)$ & $20(23.5)$ & $32(37.6)$ & $22(25.9)$ & \\
\hline $\begin{array}{l}30,000-40,000 \\
(\$ 354.9-\$ 473.3)\end{array}$ & $31(7.8)$ & $3(9.7)$ & $12(38.7)$ & $11(35.5)$ & $5(16.1)$ & \\
\hline$>40,000(>\$ 473.3)$ & $27(6.8)$ & $1(3.7)$ & $15(55.6)$ & $7(25.9)$ & $4(14.8)$ & \\
\hline \multicolumn{7}{|l|}{ Family Types } \\
\hline Nuclear & $172(43.0)$ & $14(8.1)$ & $58(33.7)$ & $57(33.1)$ & $43(25.0)$ & \multirow[t]{2}{*}{0.522} \\
\hline Joint/Extended & $228(57.0)$ & $20(8.8)$ & $62(27.2)$ & 88 (38.6) & $58(25.4)$ & \\
\hline \multicolumn{7}{|l|}{ Religion } \\
\hline Muslim & $356(89.0)$ & $27(7.6)$ & $110(30.9)$ & $132(37.1)$ & $87(24.4)$ & \multirow[t]{2}{*}{0.137} \\
\hline Non-Muslim & $44(11.0)$ & $7(15.9)$ & $10(22.7)$ & $13(29.5)$ & $14(31.8)$ & \\
\hline
\end{tabular}

2.60, 95\% CI: 1.63-4.12, $p<0.0001$; Adjusted OR = 2.91, 95\% CI: $1.61-5.23, p<0.0001)$ than the pre-elderly age group (55-59 years), and the older adults aged 70 years and more, were $323 \%$ of a higher chance (unadjusted OR: 3.50, 95\% CI: 2.18-5.62, p < 0.0001; Adjusted OR: 4.23, 95\% CI: $2.26-7.92, \mathrm{p}<0.0001$ ) of frailty (Medical Conditions) than the pre-elderly age group. Gender had a significant impact on frailty, where the risk of frailty severity was significantly higher (unadjusted OR: 2.226, 95\% CI: 1.61-3.07, p < 0.0001; Adjusted OR = 1.487, 95\% CI: 0.84$2.64, p<0.0174)$ among the female than male older adults. Monthly income of the family was also a significant predictor of older adult's frailty. The older adults from the higher income (Income> \$473.3) family found a lower risk of frailty (unadjusted OR: 0.688, 95\% CI: 0.32-1.48, $p<$ 0.339; Adjusted OR: 0.294, 95\% CI: 0.11-0.76, $p<0.011$ ). 
Table 4 Summary of Logistic Regression Model for Predicting Older Adults' Health status through frailty

\begin{tabular}{|c|c|c|c|c|c|c|}
\hline Characteristics & Unadjusted OR & $\mathrm{Cl}$ & P-value & Adjusted OR & $\mathrm{Cl}$ & P-value \\
\hline \multicolumn{7}{|l|}{ Age of the respondent } \\
\hline $55-59$ & Ref & - & - & Ref & - & - \\
\hline $60-64$ & 2.60 & $1.63-4.12$ & 0.0001 & 2.910 & $1.61-5.23$ & 0.0001 \\
\hline $65-69$ & 0.941 & $0.58-1.52$ & 0.806 & 1.217 & $0.67-2.19$ & 0.511 \\
\hline $70+$ & 3.500 & $2.18-5.62$ & 0.0001 & 4.232 & $2.26-7.92$ & 0.0001 \\
\hline \multicolumn{7}{|l|}{ Gender } \\
\hline Male & Ref & - & - & Ref & - & - \\
\hline Female & 2.226 & $1.61-3.07$ & 0.0001 & 1.487 & $0.84-2.64$ & 0.0174 \\
\hline \multicolumn{7}{|l|}{ Education } \\
\hline Illiterate & Ref & - & - & Ref & - & - \\
\hline Literate & 1.247 & $0.92-1.68$ & 0.149 & 0.993 & $0.63-1.58$ & 0.977 \\
\hline \multicolumn{7}{|l|}{ Occupation } \\
\hline Service & Ref & - & - & Ref & - & - \\
\hline Housewife/Others & 1.958 & $1.53-2.50$ & 0.0001 & 1.217 & $0.74-1.99$ & 0.437 \\
\hline \multicolumn{7}{|l|}{ Marital Status } \\
\hline Widow/Divorce & Ref & - & - & Ref & - & - \\
\hline Married & 2.636 & $1.61-4.31$ & 0.0001 & 1.043 & $0.55-1.1 .98$ & 0.898 \\
\hline \multicolumn{7}{|l|}{ Smoking Behavior } \\
\hline Non-Smoker & Ref & - & - & Ref & - & - \\
\hline Smoker & 1.20 & $0.76-1.64$ & 0.560 & 0.732 & $0.437-1.23$ & 0.236 \\
\hline \multicolumn{7}{|c|}{ Monthly Family Income in Taka (Dollars, considering \$1 = 84.52 BDT, Accessed: October 06, 2020) } \\
\hline Less than $10,000(\$ 118.3)$ & Ref & - & - & Ref & - & - \\
\hline $10,000-20,000(\$ 118-\$ 236.6)$ & 1.439 & $1.03-2.02$ & 0.035 & 0.606 & $0.357-1.03$ & 0.064 \\
\hline $20,000-30,000(\$ 236.6-\$ 354.9)$ & 1.74 & $1.12-2.71$ & 0.014 & 0.780 & $0.42-1.46$ & 0.438 \\
\hline $30,000-40,000(\$ 354.9-\$ 473.3)$ & 1.067 & $0.53-2.16$ & 0.857 & 0.502 & $0.210-1.20$ & 0.121 \\
\hline$>40,000(>\$ 473.3)$ & 0.688 & $0.32-1.48$ & 0.339 & 0.294 & $0.11-0.76$ & 0.011 \\
\hline \multicolumn{7}{|l|}{ Family Types } \\
\hline Nuclear & Ref & - & - & Ref & - & - \\
\hline Joint/Extended & 1.28 & $0.85-1.92$ & 0.231 & 1.136 & $0.73-1.78$ & 0.576 \\
\hline \multicolumn{7}{|l|}{ Religion } \\
\hline Muslim & Ref & & & & & \\
\hline Non-Muslim & 0.994 & $0.52-1.89$ & 0.98 & 0.791 & $0.38-1.64$ & 0.527 \\
\hline
\end{tabular}

\section{Discussion}

We investigated, using the Frailty Index $\left(\mathrm{FI}_{30}\right)$, the prevalence of frailty or physio-psychosocial health in Bangladeshi community-dwelling older adults and explored the associated risk factors. We found that most people in older age groups were susceptible to frailty, and at higher risk of medical conditions than the preelderly age group, which is consistent with previous studies [1, 4, 27, 43, 44]. In South Asian Context, our study presented a high prevalence of frailty (61.6\%) in older adults who are experiencing 'poor-very poor' health (moderate to severe frailty), and this prevalence is greater than other South Asian countries (India - 26\%;
Pakistan - 55.4\%; Nepal - 46.2\%; and Sri Lanka $15.2 \%)$. It is interesting that the prevalence of intermediate or pre-frail in Pakistan and Sri Lanka is consistent with our study findings $[14,18,20,45]$.

We conducted this study in a regional area of Bangladesh and the Frailty Index used predicts physiopsychosocial health for all older adults' age groups. Three studies were conducted in regional areas of Colombia (12.2\%); Mexico (10.7\%); and Turkey (7.1\%), where low prevalence of frailty was evident compared to our study [46-48]. The reasons of such low prevalence are unknown. Such low prevalence could be because of methodological issues or participant's recruitment 
process, as identified by Siriwardhana et al. (2018) that voluntary participation underestimates the true prevalence and participants aged 70 years and older are less likely participate [20]. In contrast, a large number of older adults living in a regional area participated in this study and our $\mathrm{FI}_{30}$ indices were effective in explaining their frailty and or health conditions. Health professionals may consider using the $\mathrm{FI}_{30}$ indices to develop and implement evidence-based public health programs and clinical decision making in geriatric care in regional areas of South Asia.

As suggested by existing literature, our study found frailty was associated with old age, mobility and functional status. Analysis of the association between age and frailty implies that frailty is a critical predictor for overall health and the well-being status of older adults [49-52]. According to Cloney et al. (2015), frailty metrics are effective to identify the older adult's risk of health conditions and, similarly, this study suggests that elderly persons medical conditions are more likely to increase with the advancement of age [53]. The findings of this study are comparable to the existing literature that, as measured using diverse frailty index indicators, elderly health is not even in a good position in Bangladeshi older adults [22, 25, 43, 44]. Most older adults '60-69 years' experience slightly poor to poor health, while the older adults aged 70 years and above are at risk of severe medical conditions. The implication of our findings is similar with studies conducted in Sri Lanka and Pakistan in elaborating that South Asian older adults aged 65 years and above, especially those who live in regional areas, require more medical care support as their mobility and functionality decline rapidly at this stage.

In this study, frailty indices consider various aspects of general health assessment including self-reported medical history, biomarkers and performance in daily activities. Gender was identified as a risk factor for predicting the older adults' frailty $[14,27]$. This study's findings agree on the previous studies reporting that female older adults in low-income countries, South Asia in particular, are generally reluctant about their health complexities and do not take proper initiatives for health check-ups [27, 54-56]. A considerable inconsistency in the research outcomes is that female older adults who live without a partner are more inclined to suffer medical conditions [57-59]. Investigations also reported that frailty was severe for those who have a low activity status in predicting potential health conditions, which is consistent with our study's results that frailty is associated with females who are less likely to engage in physical activities or exercise [43, 60-63].

The literature shows, as our study identifies that overall health and well-being status of the older adults is compromised with the presence of low family income; because, low family income prevents them to maintain a healthy lifestyle [43, 64-66]. About two-thirds of the world's poorer older adults live In South Asia, and they suffer from basic humanitarian problems including hunger and under-nutrition, low consumption of food, lack of housing, inadequate healthcare and illiteracy $[9,67]$. Under such circumstances, Bangladesh has the third largest population of poor older adults in the world, and about $63 \%$ of them are jobless and 15\% are engaged in daily labour, resulting in a lack of income and savings. Health conditions of the older adults often become severe for those in poor living circumstances, with limited healthcare services and home care support $[7,68]$. While other studies in South Asia did not identify the association between low family income and frailty, this study adds to the knowledge that family income is an important risk factor of frailty, therefore, suggesting strengthening the social safety nets for poor older adults.

We experienced few limitations related to this study: (i) this was cross-sectional research that carries the limitations of such studies as they have a lack of strength in cause-effect analysis; (ii) the study was conducted in one city of Bangladesh because of our limited funds; and (ii) health illiteracy of the participants contributed to a lengthy data collection period. However, we are planning to conduct a wide regional survey in our next project, which is approved by the University Research Centre (URC), SUST. Our next study could extensively investigate the clinical assessment outcomes in relation to older adult's frailty. Investigations into the influence of frailty on chronic health conditions and medical outcomes are warranted.

\section{Conclusion}

The Frailty Index not only predicts the older adults' physical health, but also measures their health-related quality of life governed by socio-demographic factors. The study findings confirm that community-dwelling older adults live in north-eastern region of Bangladesh are at high risk of frailty with two-thirds inclined to medical conditions requiring acute care. Being aged and female with low-income are influential risk factors to frailty/poor health. Patient activation strategies and primary care interventions including peerhealth education, aerobic exercise sessions and an interdisciplinary public healthcare approach should be undertaken, especially for the female and older adults living without a partner/spouse, to strengthen geriatric care support. The public health leaders should also take the initiative to engage the older adults in paid or voluntary activities. It is claimed by the authors that frailty and associated sociodemographic factors can underscore physio-psychosocial health, thus, the findings are beneficial for policymakers in developing and implementing public health interventions for the older adults in developing countries like Bangladesh. 


\section{Abbreviations}

BMl: Body Mass Index; BP: Blood Pressure; RBS: Random Blood Sugar; $\mathrm{Fl}_{30}$ : Frailty Index with 30 indicators; GDS: Geriatric Depression Scale; HBP: High Blood Pressure

\section{Acknowledgements}

We are thankful to the participants who provided time and shared their health experiences. Also, thanks go to Public Health Assistants who supported in health assessments and data collection.

\section{Authors' contributions}

MMR, MH and MNI conceptualized, drafted and reviewed the manuscript. MSA, ZF, MKH and MNH were involved in data collection, analysis and reviewing the draft manuscript. All authors read the manuscript for important intellectual context and approved the submission.

\section{Funding}

SUST-Research Center is a leading research institute in Bangladesh administered by the Shahjalal University of Science and Technology (SUST), Sylhet-3114, Bangladesh. This study was a part of a research project financed by the SUST-Research Center under the research and innovation grant project number PS/2018/1/11. The project's fund was allocated for the data collection and remuneration of the associated staffs. No fund was received for the article production from the project's budget as we do not have any fund allocation for the researchers to publish articles in an open-access journal. Any funding organization was not involved in research activities of the project.

\section{Availability of data and materials}

The datasets generated and/or analyzed during the current study are available from the corresponding author on reasonable request to meshbahur.rahman@brfbd.org

\section{Ethics approval and consent to participate}

The ethics approval including participants' approach and recruitment were granted by the Shahjalal University of Science and Technology (SUST) Research Center, Bangladesh [Project Number PS/2018/1/11]. We contacted the Ward Councilors [representative of government administrative ward] of Sylhet City Corporation and provided them with a Letter of Introduction and an Information Sheet about the research. These Councilors organized wardbased yard-gatherings in alternative days, where the Information Sheet was read out to the potential participants by the Councilors, as most of the older adults were illiterate. The Councilors also informed the older adults about the aims of the research, and introduced the researchers at the end of all the gatherings. A written Informed Consent form approved by the SUSTResearch Center was used to obtain consent from each of the older adults who expressed their interest to participant in the study. The participants who were illiterate used their thumb-print to provide consent. In relation to reviewing medical records of the participants, we contacted the Sylhet Civil Surgeon [Main authority in providing and managing healthcare for people living in Sylhet district] who considered the project's ethics approval, participants' consents and our application for accessing the participants' medical data-sets.

\section{Consent for publication}

Not applicable.

\section{Competing interests}

The authors declared no competing of interest.

\section{Author details}

'Biomedical Research Foundation, Dhaka 1230, Bangladesh. ${ }^{2}$ Basic Science Division, World University of Bangladesh, Dhaka 1230, Bangladesh. ${ }^{3}$ Flinders University Rural Health SA, College of Medicine \& Public Health, Flinders University, Bedford, South Australia, Australia. ${ }^{4}$ Asian University of Bangladesh, Dhaka, Bangladesh. ${ }^{5}$ Bangladesh Bank-The Central Bank of Bangladesh, Dhaka 1215, Bangladesh. ${ }^{6}$ Department of Statistics, Shahjalal University of Science and Technology, Sylhet 3114, Bangladesh.
Received: 8 June 2020 Accepted: 16 December 2020

Published online: 06 January 2021

\section{References}

1. Hamiduzzaman M, De Bellis A, Kalaitzidis E, Abigail W. Factors impacting on elderly women's access to healthcare in rural Bangladesh. Indian J Gerontol. 2016;30(2):235-60.

2. Rahman M. Aging and negligence in Bangladesh. J Gerontol Geriatr Res. 2017:6(3):1-2.

3. Kashikar $Y$, Nagarkar A. Prevalence and determinants of frailty in older adults in India. Indian J Gerontol. 2016;30(3):364-81.

4. Ali AA, Haq N, Chang K, Naqi S, Rafique M, Ismail M, Naseer R, Nasim A, Kumail M. Impact of obesity on frailty in older population of Karachi, Pakistan. Adv Med Dental Health Sci. 2019;2(4):52-4.

5. Devkota S, Anderson B, Soiza RL, Myint PK. Prevalence and determinants of frailty and associated comorbidities among older Gurkha welfare pensioners in Nepal. Geriatr Gerontol Int. 2017;17(12):2493-9.

6. Hamiduzzaman M, Torres S, Fletcher A, Islam MR, Greenhill J. Aging, Care and Dependency in Multimorbidity: How Relationships Affect Older Bangladeshi Women Use of Homecare and Health Services. medRxiv. 2020; Available at https://www.medrxiv.org/content/10.1101/2020.06.19.20126 078v1. Accessed 1 Nov 2020.

7. Islam MN, Nath DC. A future journey to the elderly support in Bangladesh. J Anthropol. 2012;2012:1-6.

8. Kabir M. Demographic and Economic Consequences of Aging in Bangladesh. In: Centre for Policy Dialogue. Centre for Policy Dialogue and United Nations Population Fund; 1999. p. 1-18.

9. Hamiduzzaman M, de Bellis A, Abigail W, Kalaitzidis E. Elderly women in rural Bangladesh: healthcare access and ageing trends. South Asia Res. 2018; 38(2):113-29. https://doi.org/10.1177/0262728018767018.

10. Kojima $G$, lliffe $S$, Walters K. Frailty index as a predictor of mortality: a systematic review and meta-analysis. Age Ageing. 2017;47(2):193-200.

11. Rockwood K, Mitnitski A. Frailty in relation to the accumulation of deficits. J Gerontol Biol Sci Med Sci. 2007;62. https://doi.org/10.1093/gerona/62.7.722.

12. Kim S, Jazwinski SM. Quantitative measures of healthy aging and biological age. Heal Aging Res. 2015;4(26). https://doi.org/10.12715/har.2015.4.26.

13. Mitnitski AB, Mogilner AJ, Rockwood K. Accumulation of deficits as a proxy measure of aging. Sci World J. 2001;1:323-36.

14. Kendhapedi KK, Devasenapathy N. Prevalence and factors associated with frailty among community-dwelling older people in rural Thanjavur district of South India: a cross-sectional study. BMJ Open. 2019;9(10):e032904.

15. Dasgupta A, Bandyopadhyay S, Bandyopadhyay L, Roy S, Paul B, Mandal S. How frail are our elderly? An assessment with Tilburg frailty indicator ( TFI ) in a rural elderly population of West Bengal. J Fam Med Prim Care. 2019; 8(7):2242-48.

16. Shalini T, Chitra PS, Kumar BN, Madhavi G, Reddy GB. Frailty and Nutritional Status among Urban Older Adults in South India. J Aging Res. 2020;2020: 8763413.

17. Pengpid S, Peltzer K. Prevalence and associated factors of frailty in community-dwelling older adults in Indonesia, 2014-2015. Int J Environ Res Public Health. 2019;17(1):10.

18. Yadav UN, Tamang MK, Thapa TB, Hosseinzadeh H, Harris MF, Yadav KK Prevalence and determinants of frailty in the absence of disability among older population: a cross sectional study from rural communities in Nepal. BMC Geriatr. 2019;19(1):283.

19. Siriwardhana DD, Hardoon S, Rait G, Weerasinghe MC, Walters KR. Prevalence of frailty and prefrailty among community-dwelling older adults in low-income and middle-income countries: a systematic review and metaanalysis. BMJ Open. 2018;8(3):e018195.

20. Siriwardhana DD, Weerasinghe MC, Rait G, Falcaro M, Scholes S, Walters KR. Prevalence of frailty in rural community-dwelling older adults in Kegalle district of Sri Lanka: a population-based cross-sectional study. BMJ Open. 2019;9(1):e026314

21. Begum MS. Geriatric health problems and health care seeking practice among elderly people attending one selected geriatric hospital. Bangladesh J Phisiology Pharmacol. 2007;23(1\&2):20-4.

22. Farah S, Karim M, Khatun UHS. Health problems of the elderly population in some selected urban slums of Dhaka City. J Bangladesh Coll Physicians Surg. 2015;33(4):202-6

23. Rahman MM, Mahmudur Rahman M, Taj Uddin M. Health status and modeling of urban aged population of Sylhet District in Bangladesh. 
Bioinformatics and Biostatistics for Agriculture, Health and Environment. 2017:2017:P135.

24. Rahman R. An empirical study on elderly population 's Care in Bangladesh : legal and ethical issues. J Humanit Soc Sci. 2018;23(1):1-8.

25. Islam MZ. Determinants of long term diseases suffering among the elderly population in Bangladesh. Asian J Appl Sci Eng. 2017;6(1):33-42.

26. Life L, Biswas P, Kabir ZN, Nilsson J, Zaman S. Dynamics of Health Care Seeking Behaviour of Elderly People in Rural Bangladesh. Int J Ageing and Later Life. 2006;1 (1):69-89.

27. Tareque MI, Tiedt AD, Islam TM, Begum S, Saito Y. Gender differences in functional disability and self-care among seniors in Bangladesh. BMC Geriatr. 2017:17(1):177.

28. Alam S. Elderly people in Bangladesh: Vulnerabilities, laws and policies $1 \mathrm{st}$ Draft Report. 2015. Available from: https://www.academia.edu/22978303/ Elderly_people_in_Bangladesh_Vulnerabilities_laws_and_policies_1_st_ Draft_Report. Accessed 1 Nov 2020.

29. Bangladesh Bureau of Statistics. POPULATION \& HOUSING CENSUS-2011 (ZILA REPORT : SYLHET). 2015.

30. Bishwajit G, Tang S, Yaya S, Feng Z. Participation in physical activity and back pain among an elderly population in South Asia. J Pain Res. 2017;10: 905-13.

31. Datta PB, Islam N, Paul GK. Factors responsible for the health status of elderly people : a case study in Sylhet district. Int J Med Heal Res. 2018;4(4): 72-7.

32. Barikdar A, Ahmed T, Lasker S. The Situation of the Elderly in Bangladesh. Bangladesh J Bioethics. 7(1):27-36. https://doi.org/10.3329/bioethics.v7i1. 29303.

33. Clarke $\mathrm{LH}$, Korotchenko A. Aging and the body : a review. Can J Aging. 2014;30(3):495-510.

34. Platinum Dermatology. The seven signs of ageing - platinum Dermatology. 2016. Available from: https://www.platinumdermatology.com.au/articles/theseven-signs-of-ageing/. Accessed 8 Oct 2020.

35. BBS. Population and Housing Census, 2011. National report, volume - 4, Bangladesh Bureau of Statistics (BBS) 2011. Available from: http://catalog ihsn.org/index.php/catalog/4376. Accessed 8 Oct 2020.

36. Gobbens RJJ, van Assen MALM, Luijkx KG, Wijnen-Sponselee MT, Schols JMGA. The Tilburg frailty indicator: psychometric properties. J Am Med Dir Assoc. 2010;11(5):344-55

37. Searle SD, Mitnitski A, Gahbauer EA, Gill TM, Rockwood K. A standard procedure for creating a frailty index. BMC Geriatr. 2008;8(1):24.

38. Fried LP, Tangen CM, Walston J, Newman AB, Hirsh C, Gottdiener J, et al. Frailty in older adults: evidence for a phenotype. J Gerontol A Biol Sci Med Sci. 2001;56(3):M146-56.

39. Yesavage JA, Brink TL, Rose TL, Lum O, Huang V, Adey M, et al. Development and validation of a geriatric depression screening scale: a preliminary report. J Psychiatr Res. 1983;17(1):37-49.

40. Clegg A, Bates C, Young J, Ryan R, Nichols L, Ann Teale E, et al. Development and validation of an electronic frailty index using routine primary care electronic health record data. Age Ageing. 2016;45(3):353-60.

41. Chowdhury MAB, Uddin MJ, Haque MR, Ibrahimou B. Hypertension among adults in Bangladesh: evidence from a national cross-sectional survey. BMC Cardiovasc Disord. 2016;16(1):22.

42. Bolarinwa O. Principles and methods of validity and reliability testing of questionnaires used in social and health science researches. Niger Postgrad Med J. 2015;22(4):195-201.

43. Rahman MM, Begum MR, Uddin MT, Rahman MM. Factors affecting health status of urban aged population: evidence from Sylhet, Bangladesh. Indian J Gerontol. 2018;32(1):103-18.

44. Mostafa G, Razzaque A. Determinants and causes of death of elderly people in Matlab, Bangladesh. 2002. Available from: http://iussp2005.princeton.edu/ papers/50828. Accessed 8 Oct 2020

45. Nguyen T, Cumming RG, Hilmer SN. A review of frailty in developing countries. J Nutr Health Aging. 2015;19(9):941-6.

46. Curcio C-L, Henao G-M, Gomez F. Frailty among rural elderly adults. BMC Geriatr. 2014;14:2. https://doi.org/10.1186/1471-2318-14-2.

47. Moreno-Tamayo K, Manrique-Espinoza B, Rosas-Carrasco O, Pérez-Moreno A, Salinas-Rodríguez A. Sleep complaints are associated with frailty in Mexican older adults in a rural setting. Geriatr Gerontol Int. 2017;17(12):2573-8.

48. Çakmur H. Frailty among elderly adults in a rural area of Turkey. Med Sci Monit. 2015;21:1232-42.
49. Myers V, Drory Y, Goldbourt U, Gerber Y. Multilevel socioeconomic status and incidence of frailty post myocardial infarction. Int J Cardiol. 2014;170(3):338-43.

50. Ottenbacher KJ, Graham JE, Al Snih S, Raji M, Samper-Tement R, Ostir GV, et al. Mexican Americans and frailty: findings from the Hispanic established populations epidemiologic studies of the elderly. Am J Public Health. 2009;99(4):673-9.

51. Fhon JRS, Rodriques RAP, Santos JLF, Diniz MA, Santos Dos EB, Almeida VC, et al. Factors associated with frailty in older adults: a longitudinal study. Rev Saude Publica. 2018;52:74.

52. Liang Y-D, Zhang Y-N, Li Y-M, Chen Y-H, Xu J-Y, Liu M, et al. Identification of frailty and its risk factors in elderly hospitalized patients from different wards: a cross-sectional study in China. Clin Interv Aging. 2019;14:2249-59.

53. Cloney M, D'Amico R, Lebovic J, Nazarian M, Zacharia BE, Sisti MB, et al. Frailty in geriatric Glioblastoma patients: a predictor of operative morbidity and outcome. World Neurosurg. 2016;89:362-7.

54. Shibasaki K, Kin SK, Yamada S, Akishita M, Ogawa S. Sex-related differences in the association between frailty and dietary consumption in Japanese older people: a cross-sectional study. BMC Geriatr. 2019;19(1):211.

55. Hanlon P, Nicholl BI, Jani BD, Lee D, McQueenie R, Mair FS. Frailty and prefrailty in middle-aged and older adults and its association with multimorbidity and mortality: a prospective analysis of 493737 UK biobank participants. Lancet Public Heal. 2018;3(7):e323-32.

56. Zhang Q, Guo H, Gu H, Zhao X. Gender-associated factors for frailty and their impact on hospitalization and mortality among community-dwelling older adults: a cross-sectional population-based study. PeerJ. 2018;6:e4326.

57. Gaymu J, Delbès C, Springer S, Binet A, Désesquelles A, Kalogirou S, et al. Determinants of the living arrangements of older people in Europe. Eur J Popul. 2006;22(3):241-62.

58. Kendall J, Anglewicz P. Living arrangements and health at older ages in rural Malawi. Ageing Soc. 2018;38(5):1018-40.

59. Siddique A. Views of the Elderly Regarding the Behavior by His Family Members. Medicine Today. 2014;26(2):104-10.

60. Sun F, Norman IJ, While AE. Physical activity in older people: a systematic review. BMC Public Health. 2013;13:449.

61. Cvecka J, Tirpakova V, Sedliak M, Kern H, Mayr W, Hamar D. Physical activity in elderly. Eur J Transl Myol. 2015;25(4):249-52.

62. Islam M, Rahman M. Health problems of elderly people in Bangladesh. Armed forces Med Coll. 2017:13(1):1-2.

63. Moniruzzaman M, Zaman MM, Islalm MS, Ahasan HAMN, Kabir H, Yasmin R. Physical activity levels in Bangladeshi adults : results from STEPS survey 2010. Public Health. 2016;137:131-8.

64. Vaingankar JA, Chong SA, Abdin E, Picco L, Chua BY, Shafie S, et al. Prevalence of frailty and its association with sociodemographic and clinical characteristics, and resource utilization in a population of Singaporean older adults. Geriatr Gerontol Int. 2016;17(10):1444-54.

65. Thakur R, Banerjee A, Nikumb V. Health problems among the elderly: a cross-sectional study. Ann Med Health Sci Res. 2013;3(1):19-25.

66. Uddin MT, Islam MN, Alam MJ. Bahar GU, Socio-Economic status of Elderly of Bangladesh: A Statistical Analysis. J Appl Sci. 2010;10:3060-67.

67. Hamiduzzaman M. The world is not mine: factors and issues of rural elderly Women's access in modern healthcare Services in Bangladesh; 2018.

68. Nath DC, Islam MN. New Indices: an Application Of Measuring Aging Process Of Some Asian Countries With special Reference to Bangladesh. Popul Aging. 2009;2(1-2):23-49.

\section{Publisher's Note}

Springer Nature remains neutral with regard to jurisdictional claims in published maps and institutional affiliations.

\section{Ready to submit your research? Choose BMC and benefit from:}

- fast, convenient online submission

- thorough peer review by experienced researchers in your field

- rapid publication on acceptance

- support for research data, including large and complex data types

- gold Open Access which fosters wider collaboration and increased citations

- maximum visibility for your research: over $100 \mathrm{M}$ website views per year

At BMC, research is always in progress.

Learn more biomedcentral.com/submissions 